\title{
Vulvar cancer is not a disease of the elderly: Treatment and outcome at a tertiary referral centre in South Africa
}

\author{
J L Butt, MB ChB, FCOG (SA), MMed, Cert Gynaecological Oncology (SA); M H Botha, MB ChB, FCOG (SA), \\ Cert Gynaecological Oncology (SA), PhD \\ Department of Obstetrics and Gynaecology, Tygerberg Hospital and Faculty of Medicine and Health Sciences, Stellenbosch University, \\ Cape Town, South Africa
}

Corresponding author: J Butt (jbutt@sun.ac.za)

Background. An increase in vulvar cancer in young women is attributed to infection with oncogenic human papillomavirus (HPV). South Africa (SA) has a high prevalence of HPV, and it was therefore hypothesised that women with vulvar cancer here would be younger than in high-income countries (HICs).

Objective. To describe age, cancer stage, treatment and outcome of patients with vulvar cancer at a tertiary referral centre in SA.

Methods. In a retrospective observational study, patient records of women diagnosed with vulvar cancer between 2001 and 2014 were reviewed and demographic and surgical details captured. Histology results of vulvar biopsies and resected specimens were checked for HPV changes, koilocytes and usual-type vulval intraepithelial neoplasia. Patients were restaged using the International Federation of Gynecology and Obstetrics (FIGO) 2009 staging system to allow for comparison of outcomes. Five-year disease-specific survival probability curves were generated using Kaplan-Meier analysis.

Results. The mean age of the 180 patients in the study was 52.5 years. Those who had documented HPV changes on histological specimens had a mean age of 50.4 years. More than $50 \%$ of the patients had advanced-stage disease, and $62.7 \%$ were treated with primary surgery. Five-year disease-specific survival probabilities were similar to those reported in the literature.

Conclusions. Vulvar cancer should not be regarded as a disease of the elderly in SA, as women with vulvar cancer are 10 - 15 years younger than in HICs. A large proportion of patients present with advanced-stage disease. Health professionals should be alert to vulvar lesions, especially in women with abnormal Pap smears, to reduce the morbidity and mortality of this disease.

S Afr Med J 2017;107(11):1000-1004. DOI:10.7196/SAMJ.2017.v107il1.12497

Although vulvar cancer is a rare disease, an increase in its incidence, particularly in younger women, has been reported. ${ }^{[1-3]}$ This increase in younger women has been associated with the presence of oncogenic human papillomavirus (HPV). ${ }^{[4-6]}$ There are two aetiological pathways to vulvar cancer: the first is related to vulvar non-neoplastic epithelial disorders such as lichen sclerosus in older women, while the second involves younger women and is associated with high-risk HPV. ${ }^{[5,7-9]}$

The rate of HPV infection among women in South Africa (SA) is high. Africa had the highest prevalence of HPV (22.1\%) in a large meta-analysis of women with normal cytology. A single SA study included in this meta-analysis estimated the HPV prevalence in SA women with normal cytology to be $15.5 \% .^{[10]}$ Cervical cancer incidence rates mirror HPV prevalence, and as vulvar cancer has been linked to HPV infection, it follows that the prevalence of vulvar cancer in young women may also be increased in the SA population.

International literature quotes the mean age of women with vulvar cancer to be between 64 and 70 years, but the perception in the authors' clinical unit in Cape Town, SA, is that women treated at our hospital are much younger. ${ }^{[11-13]}$

\section{Objective}

To quantify the burden of disease at a tertiary referral hospital and to describe the population of women with vulvar cancer with regard to age, cancer stage, treatment modalities and outcome.

\section{Methods}

A retrospective, descriptive observational study was undertaken. Data were collected from the records of all women diagnosed with vulvar cancer presenting to the Gynaecological Oncology Unit at Tygerberg Hospital, Cape Town, between 1 January 2001 and 31 December 2014. All histological types except melanoma were included. The patients were restaged using the 2009 International Federation of Gynecology and Obstetrics (FIGO) staging system to allow comparison. Where surgical staging was not performed, the stage was assigned based on metastatic investigations, including cytological investigation of suspicious lymph nodes and imaging results.

As HPV testing was not available at our institution, histological results of vulvar biopsies and resected specimens were checked for cellular HPV changes, koilocytes and usual-type vulvar intraepithelial neoplasia (uVIN) as well as lichen sclerosus.

Treatment of early-stage vulvar cancer was mainly surgical, including vulvectomy or radical local excision of the vulvar tumour and inguinofemoral lymphadenectomy. For advanced disease (FIGO stages 3 and 4), or if the anal or urethral sphincters were involved with cancer, the patients were treated with neoadjuvant chemotherapy to shrink the lesion and make sphincter-sparing surgery possible, or with primary chemoradiotherapy, or with an anovulvectomy. Adjuvant radiotherapy (without chemosensitisation in the first 8 years of the study) was given after surgery if histopathology confirmed inguinofemoral lymph node metastases or if the tumour-free surgical margins were $<8 \mathrm{~mm}$ and further excision was not possible.

Time to recurrence was calculated from the last date of treatment to the date of recurrence. Data were censored at the patients' last follow-up visit before 31 December 2015. Disease-specific survival 
was calculated from the date of primary treatment to the date of death, when known, or the date when the patient was considered terminally ill and no further palliative treatment other than analgesia would be offered.

\section{Statistical analysis}

Statistical analysis was carried out using IBM SPSS Statistics for Windows, version 22.0 (IBM, USA). Means were compared using Student's $t$-test, and significance was set at $p<0.05$. Survival analysis was performed using Kaplan-Meier estimates.

\section{Ethics approval}

Ethics approval was obtained from the Stellenbosch University Health Research Ethics Committee (ref. no. S13/03/047).

\section{Results}

\section{Study population}

One hundred and eighty-two women presented to Tygerberg Hospital with vulvar cancer between January 2001 and December 2014. Two women were excluded from the study; one was found to have a recurrence of vulvar cancer, with her initial diagnosis in 1992 , and the other was referred to our unit postoperatively for

\begin{tabular}{|c|c|c|}
\hline Characteristic & Patients, $n^{*}$ & \\
\hline $\begin{array}{l}\text { Age }(\mathrm{yr}) \text {, mean } \\
(\mathrm{SD}, \text { range })\end{array}$ & 180 & $52.5(15.5,24-102)$ \\
\hline Parity, median (range) & 174 & $3(0-12)$ \\
\hline Married, $n(\%)$ & 139 & $87(62.6)$ \\
\hline $\begin{array}{l}\mathrm{BMI}\left(\mathrm{kg} / \mathrm{m}^{2}\right) \text {, mean }(\mathrm{SD} \text {, } \\
\text { range) }\end{array}$ & 87 & $25.4(6.6,13.4-49.3)$ \\
\hline Smoking, $n(\%)$ & 165 & $103(62.4)$ \\
\hline \multicolumn{3}{|l|}{ Medical conditions, $n(\%)$} \\
\hline Hypertension & 180 & $72(40.0)$ \\
\hline Diabetes & 180 & $24(13.3)$ \\
\hline Asthma & 180 & $17(9.4)$ \\
\hline HIV & 169 & $40(23.7)$ \\
\hline \multicolumn{3}{|l|}{ Pap smear, $n(\%)$} \\
\hline Normal & 144 & $72(50.0)$ \\
\hline LSIL & 144 & $35(24.3)$ \\
\hline HSIL & 144 & $37(25.7)$ \\
\hline \multicolumn{3}{|c|}{$\begin{array}{l}\mathrm{SD}=\text { standard deviation; } \mathrm{BMI}=\text { body mass index; } \mathrm{LSIL}=\text { low-grade intraepithelial } \\
\text { neoplasia; } \mathrm{HSIL}=\text { high-grade intraepithelial neoplasia. } \\
\text { *Certain variables had missing data. }\end{array}$} \\
\hline
\end{tabular}

adjuvant treatment and no details of her initial presentation or surgery were available.

The mean (standard deviation (SD)) age of the women at diagnosis of vulvar cancer was 52.5 (15.5) years (range 24 - 102). The patient characteristics are shown in Table 1.

HPV changes, koilocytes and/or uVIN were documented as present in the vulvar specimens from 82 women. Nine women had histologically diagnosed lichen sclerosus. The mean age of women with underlying HPV infection was 50.4 years, which was significantly younger than that of the women with lichen sclerosus (68.6 years) $(p<0.001)$. Of the 82 women with histological changes compatible with HPV, 72 had Pap smear results available: 62.5\% (45/72) had an abnormal Pap smear, 23/72 having high-grade intraepithelial neoplasia (HSIL) and 22/72 low-grade intraepithelial neoplasia (LSIL).

\section{Presenting symptoms}

The median duration of symptoms before diagnosis was 6 months, with a wide range from incidental diagnosis at gynaecological examination for an abnormal Pap smear (7 women) to a duration of 10 years in 2 women with lichen sclerosus. Women most commonly complained of a lesion on the vulva (67.0\%), followed by pain (41.5\%) and itching (21.6\%). Fifty percent of women were seen at the oncology clinic within 18 days of diagnosis. One woman waited 2 years and presented only after traditional remedies had failed to improve her condition. Another woman was afraid to come to hospital and presented 3.5 years after diagnosis with stage 4 disease.

\section{Cancer stage}

The breakdown of patients by stage (FIGO 2009) and primary treatment modality is shown in Table 2. Stage was assigned on the basis of clinical examination, imaging and cytology in cases where patients were not surgically staged. In patients who were surgically staged, the number and size of lymph node metastases were not included in the earlier histology reports and stages $3 \mathrm{a}$ and $3 \mathrm{~b}$ could therefore not be distinguished. Ninety-six patients (53.3\%) had advanced-stage cancer of FIGO stage 3 or higher.

\section{Treatment modalities and outcome}

One hundred and thirteen patients $(62.7 \%)$ had surgery as a primary treatment, $46(40.7 \%)$ of them receiving adjuvant radiotherapy after surgery. Of all the patients treated with primary surgery, 72 (63.7\%) were free of disease at their last follow-up visit. Of the remaining 41 patients, 27 died, 18 from vulvar cancer and 9 from other causes, 6 had progressive disease at their last visit, and 8 had defaulted from further care.

Table 2. Primary treatment modalities

\begin{tabular}{|c|c|c|c|c|c|c|}
\hline \multirow[b]{2}{*}{ FIGO stage } & \multirow[b]{2}{*}{ Patients, $n(\%)$} & \multicolumn{5}{|c|}{ Primary treatment, $n$} \\
\hline & & Surgery & $\begin{array}{l}\text { Chemoradio- } \\
\text { therapy }\end{array}$ & $\begin{array}{l}\text { Neoadjuvant } \\
\text { chemotherapy }\end{array}$ & Palliative care & $\begin{array}{l}\text { Defaulted } \\
\text { treatment }\end{array}$ \\
\hline 1a & $10(5.5)$ & 10 & 0 & 0 & 0 & 0 \\
\hline $1 \mathrm{~b}$ & $61(33.9)$ & 53 & 1 & 2 & 1 & 4 \\
\hline 2 & $13(7.2)$ & 8 & 1 & 2 & 2 & 0 \\
\hline $3 a+3 b$ & $41(22.8)$ & 29 & 2 & 2 & 3 & 5 \\
\hline $3 c$ & $14(7.8)$ & 9 & 0 & 1 & 2 & 2 \\
\hline 4ai & $14(7.8)$ & 3 & 2 & 3 & 5 & 1 \\
\hline 4aii & $17(9.4)$ & 1 & 0 & 5 & 9 & 2 \\
\hline $4 \mathrm{~b}$ & $10(5.6)$ & 0 & 1 & 0 & 8 & 1 \\
\hline Total & $180(100)$ & 113 & 7 & 15 & 30 & $15^{*}$ \\
\hline
\end{tabular}




\begin{tabular}{|c|c|c|c|c|c|c|c|}
\hline \multirow[b]{2}{*}{ FIGO stage } & \multirow[b]{2}{*}{ Patients, $N$} & \multirow[b]{2}{*}{$\begin{array}{l}\text { Patients with } \\
\text { primary } \\
\text { surgery, } N\end{array}$} & \multicolumn{4}{|c|}{ Type of surgery, $n$} & \multirow[b]{2}{*}{$\begin{array}{l}\text { Patients with recurrence } \\
\text { of disease after surgery, } \\
n(\%)\end{array}$} \\
\hline & & & $\begin{array}{l}\text { Nodal } \\
\text { excision only }\end{array}$ & $\begin{array}{l}\text { Excision } \\
\text { of vulvar } \\
\text { tumour }\end{array}$ & $\begin{array}{l}\text { Tumour }+ \\
\text { nodal excision }\end{array}$ & $\begin{array}{l}\text { Ano- } \\
\text { vulvectomy + } \\
\text { nodes }\end{array}$ & \\
\hline 1 & 71 & 63 & & 19 & 44 & & $14(22.2)$ \\
\hline 2 & 13 & 8 & 1 & & 4 & 3 & $0(0)$ \\
\hline 3 & 55 & 38 & 3 & & 28 & 7 & $15(39.5)$ \\
\hline 4 & 41 & 4 & & & 3 & 1 & $2(50.0)$ \\
\hline Total & 180 & 113 & 4 & 19 & 79 & 11 & $31 / 105^{*}(29.5)$ \\
\hline
\end{tabular}

Seven patients had primary chemoradiotherapy as treatment. They received external-beam radiotherapy of 45 Gy plus additional electron therapy to the vulva, with sensitisation with cisplatin or mitomycin $\mathrm{C}$ and 5-fluorouracil. Four of these patients were free of disease at followup, 2 died of disease and 1 defaulted from further care.

Fifteen patients were treated with neoadjuvant chemotherapy (NACT), regimens including various combinations of vincristine, bleomycin, mitomycin $\mathrm{C}$, cisplatin and 5-fluorouracil. One patient died of an arterial occlusion during her chemotherapy course. Surgery was carried out in 6 patients after NACT. Radiotherapy was given to 3 patients after NACT where surgery was not feasible. Palliative radiotherapy was given to 2 patients who had progressive disease after NACT. In total, 3 patients were free of disease at their last follow-up visit, 2 patients had progressive disease, 7 patients died and 3 defaulted from further treatment.

Surgical excision of the tumour usually involved vulvectomy in the first few years of the study and radical local excision thereafter. Lymphadenectomy included inguinal and femoral nodal dissection, but not dissection of the pelvic nodes. Unilateral lymphadenectomy was only performed in 3 patients with stage $1 \mathrm{~b}$ disease. The surgical procedures performed and the number of recurrences in patients who had primary surgery are shown in Table 3.

\section{Recurrence and survival}

Forty-one patients had a recurrence of disease after treatment. The median time to recurrence was 308 (range 18 - 3 398) days. After treatment of the recurrence, 9 patients, who underwent surgical resection of the recurrent tumour, had a complete response, 5 patients were living with disease, 26 patients died from vulvar cancer and 1 patient with disease died of pulmonary tuberculosis.

Overall, 54 of the 153 patients with known outcome (23 patients defaulted from care after their first oncology clinic visit or directly after primary treatment) died from vulvar cancer during the study period. The overall 5 -year probability of survival for all stages was $58.8 \%$. The survival curves for each stage are shown in Fig. 1. Fiveyear survival probabilities were $91.2 \%$ for stage $1,82.5 \%$ for stage 2 , $41.0 \%$ for stage 3 and $10.9 \%$ for stage 4 .

\section{Discussion}

The main finding of this retrospective study was that women referred to Tygerberg Hospital with vulvar cancer are on average 10 - 15 years younger than women with vulvar cancer in high-income countries. The mean (SD) age of women with at Tygerberg Hospital was 52.5 (15.5) years. The median age in a Surveillance, Epidemiology and End Results (SEER) database study from the USA was 67 years (2003 - 2007), the median age from a nationwide database in The Netherlands was 70.4 years (1992 - 2005), and the average age

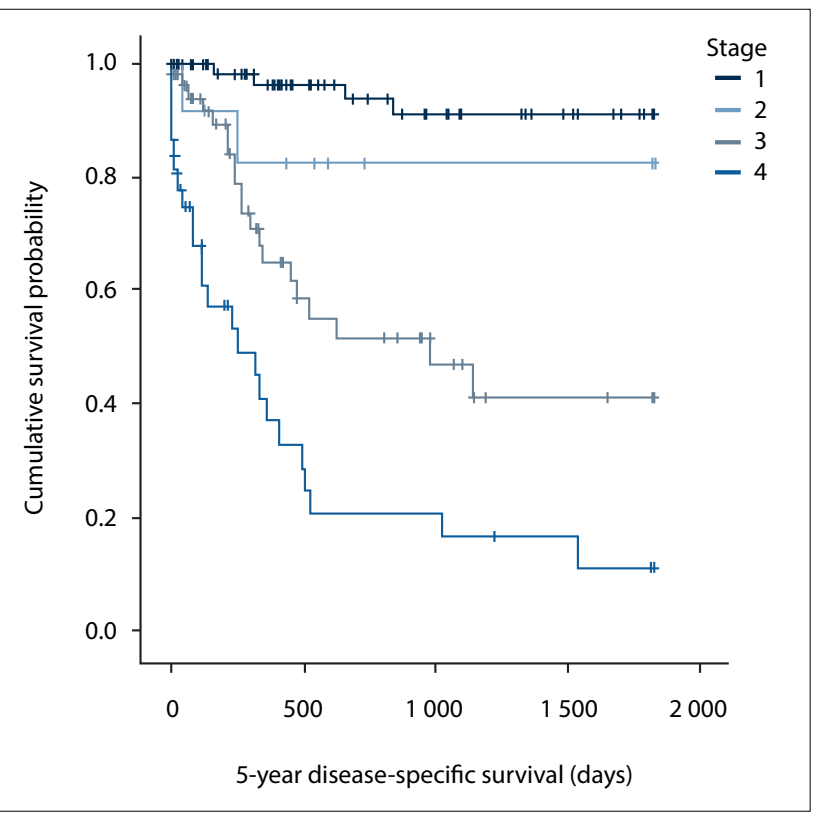

Fig. 1. Five-year disease-specific survival according to International Federation of Gynecology and Obstetrics (FIGO) stage.

in Australia was 64 years (1988 - 2009). ${ }^{[11-13]}$ In a small study of 37 patients in India the average age was 55.4 years, which is more comparable to our study. ${ }^{[14]}$

The reason for the age discrepancy between our study and studies in developed countries may be the high rate of HPV infection in the SA population. Women with HPV-related vulvar cancer are known to be younger than those with cancers originating from epithelial disorders such as lichen sclerosus. ${ }^{[8]}$ In a comparison between HPVpositive and HPV-negative vulvar cancers, Gargano et al. ${ }^{[4]}$ found the median ages of women to be 61 and 75 years, respectively. Although formal testing for HPV in our study was not possible, histological findings compatible with underlying HPV were present in 82 women. These women were significantly younger (50.4 years) than those with lichen sclerosus (68.6 years) $(p<0.001)$.

Fifty percent of women with vulvar cancer had an abnormal (LSIL or HSIL) Pap smear, which is an indication of the high prevalence of HPV infection in this population. The prevalence of HSIL in the general population in the Western Cape Province of SA is 4.2 $5.2 \%$, according to National Health Laboratory Services statistics (G Neethling, personal communication 19 May 2017). Tobacco smoking, another risk factor for HPV acquisition, was reported by $62.4 \%$ of women with vulvar cancer in our study, compared with $26.8 \%$ of females in the Western Cape in a recent study. ${ }^{[15]}$ HIV 
infection was diagnosed in $23.7 \%$ of women with vulvar cancer, which is also higher than the background prevalence of $7.8 \%$ of adults or $16.9 \%$ of antenatal patients in the Western Cape in 2012. ${ }^{[16,17]}$ The link between HIV and HPV is well known and has been described in many studies on cervical cancer.

Although the median duration of patient-reported symptoms before diagnosis was only 6 months, $53.3 \%$ of women had advancedstage cancer of FIGO stage 3 or higher. The literature reports that approximately a third of women present with advanced-stage cancer, which was reported in $26.2 \%$ of 394 women from Queensland, Australia, $37.9 \%$ of 269 women from The Netherlands, and $32.4 \%$ of 8101 women from the SEER registry. ${ }^{[11,13,18]}$ As stage and lymph node status are the main prognostic predictors in vulvar cancer, further studies need to address the reasons for late presentation of our patients to our institution if we are to improve survival. ${ }^{[19]}$

Surgery was the most common treatment modality employed to treat women with vulvar cancer $(n=113,62.7 \%)$. For locoregional disease, vulvar surgery (radical local excision with adequate margins) and inguinofemoral lymphadenectomy, or a sentinel node procedure in appropriate patients, remains the treatment of choice for the best survival outcome. ${ }^{[20]} \mathrm{A}$ few patients were treated with primary radiotherapy $(n=7)$ or NACT $(n=15)$, with varying responses. A Cochrane review comparing treatment modalities in advancedstage cancer found no difference in survival between primary surgery, neoadjuvant chemoradiation and primary chemoradiation, but analyses were restricted to single studies in each comparison. ${ }^{[19]}$ NACT has also been utilised in advanced-stage cancer, mainly to decrease tumour size in order to optimise complete surgical resection; however, the studies are all small and have not shown any evidence that survival is improved. ${ }^{[21]}$ Most studies address survival outcomes in older women, but the optimal management of vulvar cancer in young women, particularly with respect to physical and sexual aspects of quality of life, still needs to be addressed.

Recurrence of disease after treatment occurred in $33.3 \%$ of women who were followed up. This is in keeping with other reported studies, where recurrence occurred in approximately one-third of patients. ${ }^{[22]}$ Recurrence indicated a poor prognosis, as 26 of the 41 patients died. The 9 patients with complete response after recurrence all had the recurrent tumour removed surgically, 7 from the vulva and 2 from the groin. Groin recurrence has been associated with a 5-year survival rate of $0-8 \%{ }^{[23]}$ Seventy-eight percent of recurrences occurred within the first 16 months after treatment. Patients should be closely followed up during this period so that cancer recurrence can be recognised timeously and early surgical treatment implemented where possible.

The survival statistics in this study are similar to those reported in the literature ${ }^{[13]} \mathrm{A}$ large difference in survival probability between FIGO stage 2 (negative inguinofemoral lymph nodes) and stage 3 (metastatic disease in lymph nodes) can be observed, showing that positive lymph nodes significantly worsen prognosis. ${ }^{[2,25]}$

\section{Study strengths and limitations}

Vulvar cancer is a rare disease, and accrual of a sizeable cohort of patients for a study is difficult. However, a significant number of patients with vulvar cancer are referred to, treated and followed up at our institution, a referral centre in a region of high HPV prevalence. Although the FIGO stage allocation changed twice over the time of this study, all the patients were restaged according to the latest (2009) staging system, and they were managed in the same cancer unit, where treatment protocols remained similar over the time period of the study, allowing for comparison and increasing the accuracy of survival analysis.
The study was limited by its retrospective design, including missing patient records and data, unavailability of laboratory results and loss of patients to follow-up. Although the complications of the various treatments were included in the data collection, the accuracy of these data was uncertain and further analyses were not performed. HPV testing was not available at the time of this study.

Because vulvar cancer is a rare disease, this cohort of patients will greatly add to the body of knowledge on the epidemiology and treatment of women with vulvar cancer.

\section{Conclusions}

In SA, vulvar cancer is not a disease of the elderly. Healthcare professionals should take cognisance of women's symptoms, examine patients, and have a high index of suspicion of malignancy in vulvar lesions in younger women, especially those with abnormal Pap smears. It is essential that patients are diagnosed at an earlier stage if we are to reduce the morbidity of treatment and the mortality from vulvar cancer.

With the proven link of vulvar cancer to HPV, further research is necessary to determine the proportion of disease attributable to HPV in our setting, as well as to identify the strains of HPV involved. In the future, there may be a reduction in vulvar cancer as a result of introduction of the HPV vaccine. Surgical management of early-stage disease has a good prognosis, but the most appropriate and least morbid treatment for SA's young population of women with advanced disease needs to be elucidated.

Acknowledgements. The authors thank Ms T Esterhuizen, Biostatisician, Centre for Evidence-based Health Care, Stellenbosch University, for statistical analysis of the data.

Author contributions. MB conceived the idea of and co-ordinated the study, JB researched the literature, collected the data, implemented the data analysis and drafted the initial article, MB contributed to revisions of the article, and both authors approved the final version for submission. Funding. None.

Conflicts of interest. None.

1. Bodelon C, Madeleine MM, Voigt LF, Weiss NS. Is the incidence of invasive vulvar cancer increasing in the United States? Cancer Causes Control 2009;20(9):1779-1782. https://doi.org/10.1007/s10552-009$9418-8$

2. Messing MJ, Gallup DG. Carcinoma of the vulva in young women. Obstet Gynecol 1995;86(1):51-54. https://doi.org/10.1016/0029-7844(95)00101-V

Lai J, Elleray R, Nordin A, et al. Vulval cancer incidence, mortality and survival in England: Age-related trends. Br J Obstet Gynaecol 2014;121(6):728-738; discussion 739. https://doi.org/10.1111/1471-
trits trends. $\mathrm{Br}$. $\mathrm{T}$ O

4. Gargano JW, Wilkinson EJ, Unger ER, et al. Prevalence of human papillomavirus types in invasive vulvar cancers and vulvar intraepithelial neoplasia 3 in the United States before vaccine introduction. J Low cancers and valvar ind

Genit Tract Dis 2012;16(4): Monk BJ, Burger RA, Lin F, Parham G, Vasilev SA, Wilczynski SP. Prognostic significance of human papillomavirus DNA in vulvar carcinoma. Obstet Gynecol 1995;85(5):709-71

6. Al-Ghamdi A, Freedman D, Miller D, et al. Vulvar squamous cell carcinoma in young women: A clinicopathologic study of 21 cases. Gynecol Oncol 2002;84(1):94-101. https://doi.org/10.1006/ gyno. 2001.6466

7. Trimble CL, Hildesheim A, Brinton LA, Shah KV, Kurman RJ. Heterogeneous etiology of squamous carcinoma of the vulva. Obstet Gynecol 1996;87(1):59-64. https://doi.org/10.1016/0029-7844(95)00351-7 8an der Avoort IA, Shirango H, Hoevenaars BM, et al. Vulvar squamous cell carcinoma is a multifactorial disease following two separate and independent pathways. Int J Gynecol Pathol 2006;25(1):22-29. https:// doi.org/10.1097/01.pgp.0000177646.38266.6a

9. Robinson Z, Edey K, Murdoch J. Invasive vulval cancer. Obstet Gynaecol Reprod Med 2011;21(5):129136. https://doi.org/10.1016/j.ogrm.2011.02.003

10. De Sanjosé S, Diaz M, Castellsagué X, et al. Worldwide prevalence and genotype distribution of cervical . De Sanjosé S, Diaz M, Castellsagué $\mathrm{X}$, et al. Worldwide prevalence and genotype distribution of cervical
human papillomavirus DNA in women with normal cytology: A meta-analysis. Lancet Infect Dis human papillomavirus DNA in women with normal cytology:

1. Ramanah R, Lesieur B, Ballester M, Darai E, Rouzier R. Trends in of late-stage squamous cell vulvar Ramanah R, Lesieur B, Ballester M, Darai E, Rouzier R. Trends in of late-stage squamous cell vulvar
carcinomas: Analysis of the surveillance, epidemiology, and end results (SEER) database. Int J Gynecol Cancer 2012;22(5):854-859. https://doi.org/10.1097/IGC.0b013e318249bce6

12. Van de Nieuwenhof HP, Massuger LF, van der Avoort IA, et al. Vulvar squamous cell carcinoma development after diagnosis of VIN increases with age. Eur J Cancer 2009;5(5):851-856. https://doi. org/10.1016/j.jca.2008.11.037

13. Tan J, Chetty N, Kondalsamy-Chennakesavan S, et al. Validation of the FIGO 2009 staging system for carcinoma of the vulva. Int J Gynecol Cancer 2012;22(3):498-502. https://doi.org/10.1097/ IGC.0b013e318241d994

14. Bafna UD, Devi KU, Naik A, Hazra S, Sushma N, Babu N. Carcinoma of the vulva: A retrospective review of 37 cases at a regional cancer centre in South India. J Obstet Gynaecol 2004;24(4):403-407. https://doi. org $/ 10.1080 / 01443610410001685547$ 
15. Reddy P, Zuma K, Shisana O, Jonas K, Sewpaul R. Prevalence of tobacco use among adults in South Africa: Results from the first South African National Health and Nutrition examination survey. S Afr Med J 2015;105(8):648-655. https://doi.org/10.7196/SAMJnew.7932

16. Shisana, O, Rehle, T, Simbayi LC, et al. South African National HIV Prevalence, Incidence and Behaviour Survey, 2012. Cape Town: HSRC Press, 2014.

17. National Department of Health. The National Antenatal Sentinel HIV and Syphilis Prevalence Survey, South Africa 2011. Prection

18. Van der Steen S, van de Nieuwenhof HP, Massuger L, Bulten J, de Hullu JA. New FIGO staging system . Van der Steen S, van de Nieuwenhof HP, Massuger L, Bulten J, de Hullu JA. New FIGO staging system
of vulvar cancer indeed provides a better reflection of prognosis. Gynecol Oncol 2010;119(3):520-525. https://doi.org/10.1016/j.ygyno.2010.08.03

19. Gadducci A, Tana R, Barsotti C, Guerrieri ME, Genazzani AR. Clinico-pathological and biological prognostic variables in squamous cell carcinoma of the vulva. Crit Rev Oncol Hematol 2012;83(1):7183. https://doi.org/10.1016/j.critrevonc.2011.09.003

20. Woelber L, Kock L, Gieseking F, et al. Clinical management of primary vulvar cancer. Eur J Cancer 2011;47(15):2315-2321. https://doi.org/10.1016/j.ejca.2011.06.007

21. Shylasree TS, Bryant A, Howells RE. Chemoradiation for advanced primary vulval cancer. Cochrane Database Syst Rev 2011, Issue 4. Art. No.: CD003752. https://doi.org/10.1002/14651858.CD003752.pub3
22. Deppe G, Mert I, Winer IS. Management of squamous cell vulvar cancer: A review. J Obst Gynaecol Res 2014;40(5):1217-1225. https://doi.org/10.1111/jog.12352

23. Coulter J, Gleeson N. Local and regional recurrence of vulval cancer: Management dilemmas. Best Pract Res Clin Obstet Gynaecol 2003;17(4):663-681. http://dx.doi.org/10.1016/S1521-6934(03)00050-6

24. Woelber L, Eulenburg C, Choschzick M, et al. Prognostic role of lymph node metastases in vulvar cancer and implications for adjuvant treatment. Int J Gynecol Cancer 2012;22(3):503-508. https://doi.
cantions cancer and implications for adjuvan
org $/ 10.1097 / \mathrm{IGC} .0 \mathrm{~b} 013 \mathrm{e} 31823 \mathrm{eed} 4 \mathrm{c}$

25. Oonk MH, van Hemel BM, Hollema $\mathrm{H}$, et al. Size of sentinel-node metastasis and chances of nonsentinel-node involvement and survival in early stage vulvar cancer: Results from GROINSS-V, multicentre observational study. Lancet Oncol 2010;11(7):646-652. https://doi.org/10.1016/\$14702045(10)70104-2

Accepted 9 June 2017. 